\title{
Review of The State of Food Security and Nutrition in the World, 2019
}

\author{
Safeguarding Against Economic Slowdowns and Downturns
}

By Florence Egal

FAO, WHO, UNICEF and WFP have jointly produced for the third time a yearly report on The State of Food Security and Nutrition in the World, saying that the 2030 Agenda for Sustainable development puts forward a transformational vision for a world that is changing. This also reaffirms their commitment to work together to overcome emerging challenges and to free the world from hunger, food insecurity and malnutrition.

Recent editions of the report showed that the decline in hunger the world had enjoyed for over a decade was at an end, and that hunger was again on the rise. While the prevalence of undernourishment has stabilized slightly below 11 percent - on the rise in Africa to almost 20\%, in Latin America and the Caribbean still under 7\%, and more than 12\% in Western Asia -more than 820 million people in the world are still hungry today.

For the first time, the report uses the Food Insecurity Experience Scale (FIES) to estimate the prevalence of moderate or severe food insecurity. People experiencing even moderate food insecurity face uncertainties about their ability to obtain food, and have been forced to compromise on the quality and/or quantity of the food they consume.

In total, 2 billion people - either suffering from hunger or affected by moderate levels of food insecurity - are estimated to be food insecure (they do not have regular access to safe, nutritious and sufficient food). This includes 8 percent of the population in North America and Europe.

Overweight and obesity continue to increase in all regions, particularly among school-age children and adults. Food insecurity is a key determinant of all forms of malnutrition. In upper-middle- and high-income countries in particular, living in a food-insecure household is a predictor of obesity in school-age children, adolescents, and adults.

Previous reports have shown that conflict and climate variability and extremes are exacerbating the above trends. But the 2019 report, subtitled Safeguarding Against Economic Slowdowns and Downturns, focuses on the uneven pace of economic recovery and continuing poor economic performance in many countries after the 2008-2009 global economic downturn. 
During the last five years, increasing attention has been given to the links between food systems and nutrition (the State of the Food and Agriculture 2013 Food systems for better nutrition, ICN2, HLPE report on Nutrition and Food Systems and ongoing elaboration of Voluntary Guidelines on Food systems and Nutrition) and the need for sustainable food systems which bring together economic, social and environmental dimensions.

The 2019 State of Food Security and Nutrition Report advocates for country approaches and recommends that priority be given to countries relying heavily on primary commodity exports and/or imports. It advocates for economic and social policies to counteract the effects of adverse economic cycles when they arrive, while avoiding cuts in essential services, such as health care and education, at all costs. This will require pro-poor and inclusive structural transformation. Food security and nutrition concerns should be integrated into poverty reduction efforts, while ensuring that reducing gender inequalities and social exclusion of population groups is either the means to, or outcome of, improved food security and nutrition.

While the recommendations in the previous paragraph have the merit of integrating a variety of national economic and social strategies - which were until recently usually disconnected - and therefore should generate a synergistic effect, environment and biodiversity are missing. It is thus unlikely that their implementation will alone reorient existing food systems and unblock the SDG path towards 2030. The stagnation observed in the last three years may well reflect the limitations of classical development policies.

A change of approach is needed if we still hope to "end hunger, achieve food security and improved nutrition" by 2030 (SDG2). We need to go beyond the current focus on national approaches and give priority to the food and nutrition security and resilience of - often cross-border - "hotspot” areas affected by natural disasters and conflicts. Territorial approaches to development have been gaining traction in the last decades within international organizations and among development partners. ${ }^{1}$ Multi-sectoral and multistakeholder approaches -- implemented at an adequate spatial level -- appear to be a more appropriate conceptual, analytical and operational framework for understanding and addressing complexity and promoting sustainability.

In the present context, it would make sense that environmentalists and food and nutrition professionals join forces in homogenous bioregions ${ }^{2}$, which often cut across national borders. So would the relocalisation of economies with the aim of providing healthy diets, social services, jobs, managing the environment and biodiversity, and increasing resilience. The territorial perspective takes into consideration multiple levels of spatial organization, connecting local, regional, national and international scales, as well as the effects and impacts of globalization. This calls for a paradigm shift from the governance of disconnected rural and urban spaces and separate authorities, to one based on public

\footnotetext{
1 https://collaboratif.cirad.fr/alfresco/s/d/workspace/SpacesStore/6daa60e1-d89e-4a59-9bfdff5f66a93130/TP4D_vENG.pdf

${ }^{2}$ http://www.eeeee.net/bioregionalism.htm
} 
interest and multi-stakeholder governance mechanisms that allow all groups of actors to take part in the decision-making process across sub-national and national levels of government.

Concretely this will mean a change in governance and bringing new actors to the table, in particular mayors and local authorities to coordinate territorial approaches for healthy diets and economic development. It will also mean revisiting the legal, regulatory and financial systems which underlie existing food systems, and developing a new kind of research. ${ }^{3}$

This obviously does not mean abandoning strategies which have proven effective, but reorienting and articulating them and complementing them with a comprehensive approach which is based on local practice and experience and brings together environmental, social and economic dimensions. And this requires a different way of thinking about development.

3 http://www.ipes-food.org/_img/upload/files/IPES\%2010\%20Principles\%20of\%20SFS.pdf 